\title{
HUBUNGAN DUKUNGAN KELUARGA DENGAN KUALITAS HIDUP LANSIA
}

\author{
Brenda Sophia Panjaitan ${ }^{1}$, Mori Agustina br Perangin-angin ${ }^{2}$ \\ Email : panjaitanbrenda@gmail.com
}

\begin{abstract}
Abstrak
Lanjut usia merupakan fase terakhir dalam kehidupan yang akan mengalami kemunduran yang mengakibatkan melemahnya otot, serta timbulnya penyakit degeneratif, mengalami kecemasan dan depresi sehingga banyak dari lansia yang membutuhkan dukungan dari orang lain. Dukungan dari keluarga menjadi unsur penting untuk memotivasi lansia, meningkatkan rasa percaya diri, mendampingi lansia dalam memenuhi kebutuhan mereka dan menghadapi masalah mereka. Tingginya dukungan yang diterima dari keluarga maka kualitas hidup lansia akan meningkat. Penelitian ini bertujuan untuk mengetahui hubungan dukungan keluarga terhadap kualitas hidup lansia. Metode penelitian menggunakan analisis deskripsi korelasi. Responden penelitian berjumlah 32 orang, laki-laki dan perempuan yang telah berusia 60 tahun atau lebih serta mampu berkomunikasi dengan baik dan mampu mengisi kuesioner mandiri. Pengumpulan data menggunakan kuesioner FSS (Family Support Scale) for elderly people untuk mengukur dukungan keluarga dan untuk mengukur kualitas hidup menggunakan WHOQOL-BREF. Hasil penelitian menunjukkan tidak ada hubungan antara dukungan keluarga dengan kualitas hidup lansia ( $\mathrm{p}=0.204)$. Dalam penelitian ini sebagian besar lansia memiliki dukungan keluarga yang buruk namun memiliki kualitas hidup yang baik. Saran peneliti agar penelitian selanjutnya dapat membahas berbagai faktor dimensi kualitas hidup lansia untuk dapat mengetahui dengan jelas dimensi yang paling berpengaruh terhadap kualitas hidup lansia.
\end{abstract}

Kata Kunci : Dukungan Keluarga, Kualitas Hidup, Lansia

\section{Abstract}

Elderly is the last phase in life that will experience setbacks which result in muscles weakness, and the onset degenerative disease, experiencing anxiety and depression so that many of the elderly need support from others. Support from family is an important element to motivate the elderly, increase selfconfidence, assist the elderly in meeting their needs and solving their problems. High family support will improve the quality of life of the elderly. This study aims to determine the relationship between family and quality of life of the elderly. The research method uses correlation description analysis. Research respondent totalled 32 people, men and women who were 60 years old or more and able to communicate well and were able to fill out questionnaires independently. Measuring instruments to collect data using the FSS (Family Support Scale) for elderly people to measure family support and to measure quality of life using the WHOQOL-BREF. The results showed that there was no relationship between family support and the quality of life of the elderly $(p=0.204)$. This research shows that most of the elderly have a bad family support, but have a good quality of life. Researchers suggest that further research can discuss various dimensional factors of the quality of life of the elderly in order to be able to clearly identify the dimensions that most influence the quality of life of the elderly.

Keyword: Elderly, Family Support, Quality of Life 


\section{PENDAHULUAN}

Menurut Undang-Undang Republik Indonesia Nomor 13 tahun 1998 tentang kesejahteraan lanjut usia, yang dimaksud dengan lanjut usia adalah seseorang yang telah mencapai 60 tahun atau lebih dan merupakan tahap terakhir dari kehidupan setiap individu. Klasifikasi batasan lanjut usia menurut World Health Organization meliputi usia pertengahan (middle age) 44-59 tahun, lanjut usia (elderly) 60-74 tahun, dan lanjut usia sangat tua (very old) 90 tahun atau lebih (Radiani, 2018).

Jumlah presentasi lansia secara global pada tahun 2019 adalah 9,1\% dan akan terjadi peningkatan pada tahun 2030 dengan jumlah presentase 11,37\% (WPP, 2019). Berdasarkan statistik penduduk lanjut usia di Indonesia meningkat sekitar dua kali lipat (1971-2019), yakni menjadi 9,6 persen (25 juta lebih) dimana lansia muda (60-69 tahun) mencapai 63,82\%, lansia madya (70-79 tahun) dan lansia tua (80 tahun lebih) dengan masing-masing presentasi 8,50\% (Maylasari et al., 2019). Presentasi penduduk di kota Bogor pada tahun 2018 adalah 1.096.828 penduduk dan diantaranya terdapat 84.543 jiwa dengan rentan usia 60 tahun bahkan lebih (BPS Kota Bogor, 2019).

Sehubungan dengan proses penuaan, lansia akan mengalami proses kemunduran yang mengakibatkan lemahnya otot, kemunduran fisik serta berbagai penyakit degeneratif, faktor tersebut mempengaruhi kualitas hidup lansia secara progresif (Prima et al., 2019) Kemunduran yang terjadi menjadi alasan bagi lansia bergantung pada orang lain, menarik diri dari kegiatan kemasyarakatan, dan menjadi cemas akibat pensiun (Kaunang, 2019).

Normalnya usia yang masih produktif akan dengan mudah mengatasi perubahan yang lansia alami. Namun, ketidaksesuaian kondisi lansia dengan harapan mereka dapat menyebabkan orang lanjut usia mengalami depresi (Kiik et al., 2018). Itu terjadi karena mekanisme adaptasi yang kurang pada lansia dalam menghadapi perubahan yang akan membawa kualitas hidup lansia kearah yang berbeda (Wikananda, 2017). Pada umumnya, lansia di Indonesia tinggal bersama keluarga. Lansia merupakan individu yang rentan juga sensitif dan memerlukan dampingan karena keterbatasan kesehatan (Kaakinen, 2010).

Kualitas hidup adalah persepsi dari individu dalam kehidupannya sebagai suatu terminologi yang menunjukkan kondisi kesehatan baik fisik, sosial, mental individu serta kemampuan dalam melaksanankan tugas seharihari (Imanda, 2016). Unsur yang mempengaruhi kualitas hidup sangat luas dan kompleks. Menurut WHO, indikator Quality of Life terdiri dari 4 aspek yaitu, kesehatan fisik, kesehatan psikologis, hubungan sosial dan lingkungannya (Lara \& Hidajah, 2017).

Pada umumnya lansia membutuhkan seseorang untuk mengerti dengan kondisi yang 
dialami, keluarga dapat menjadi pendengar yang baik untuk mendengarkannya bercerita serta memenuhi kebutuhannya (Luthfa, 2018). Dukungan dari keluarga menjadi unsur penting untuk meningkatkan rasa percaya diri dan memotivasi lansia. Keluarga dapat melibatkaan lansia untuk membuat keputusan serta memecahkan masalah bersama, memberikan kebebasan dalam perubahan fisik dan mental, memberikan ruang dan waktu dari setiap anggota keluarga (Oktowaty, 2018). Penelitian terdahulu mengenai "Hubungan Dukungan Keluarga Terhadap Kualitas Hidup lansia" menyatakan bahwa adanya hubungan dukungan keluarga terhadap kualitas hidup lansia (Khorni, 2017; Ningrum, 2017; Octaviani, 2017). Penelitian mengenai hubungan dukungan keluarga terhadap kualitas hidup lansia telah banyak dilakukan di Indonesia dengan hasil yang berbeda.

GMAHK Bogor merupakan tempat beribadah sekelompok jemaat dengan jumlah 251 orang dan $14 \%$ diantaranya adalah lansia. Lansia di tempat ini pada umumnya tinggal bersama dengan keluarga, sebagian besar telah pensiun dan bergantung pada keluarga. Oleh karena itu peneliti ingin meneliti di tempat ini dengan tujuan untuk mengetahui apakah terdapat hubungan antara dukungan keluarga kualitas kualitas hidup lansia.

\section{METODE}

Penelitian ini dilakukan di Gereja Masehi Advent Hari Ketujuh (GMAHK) Bogor dengan jumlah sampel sebanyak 32 lansia. Penelitian yang dilakukan menggunakan metode analisis deskriptif dan pengambilan sampel dengan cara total sampling. Untuk mengukur korelasi antar variabel, menggunakan uji korelasi Spearman. Penelitian ini dilakukan pada lansia yang berusia 60 tahun keatas, mampu berkomunikasi dengan baik dan mampu mengisi kuesioner mandiri. Penelitian ini telah lulus etik dari Universitas Advent Indonesia

Pengumpulan data menggunakan instrumen WHOQOL-BREF dan FSS (Family Support Scale) for elderly people. Instrumen kualitas hidup diadopsi dari WHOQOL-100 yaitu WHOQOL-BREF menjadi 26 pertanyaan yang berbentuk skala likert serta telah di terjemahkan ke dalam Bahasa Indonesia. Alat ukur WHOQOL-BREF merupakan alat ukur yang valid dengan nilai validitas $(r=0,89-0,95)$ dan reliable $(r=0,66-0,87)$. Hasil transformasi skor dari masing-masing domain di akumulasi menjadi 4 kategori nilai yaitu: (1) Skor < 33 termasuk dalam kategori kualitas hidup rendah, (2) Skor $\geq 33$ dan $<67$ termasuk dalam kategori kualitas hidup sedang, (3) Skor $\geq 67$ termasuk dalam kategori kualitas hidup tinggi (Kathiravellu, 2016). Instrumen WHOQOLBREF tersebut mampu menjelaskan variasi dari data yang di kumpulkan sebesar 52,9\%-61,4\% (Lara \& Hidajah, 2017). Instrumen dukungan 
keluarga yang digunakan FSS for elderly people dengan 20 pertanyaan. Sifat psikometri instrumen telah dikonfirmasi melalui terjemahan belakang, penilaian, kesesuaian budaya, penelitian validitas konten, dan konfirmasi reliabilitas menggunakan konfirmasi reliabilitas menggunakan program SPSS (Uddin \& Bhuiyan, 2019).

\section{HASIL}

Tabel 1. Karakteristik Responden Berdasarkan Usia, Jenis Kelamin, Suku, Pendidikan, Tempat Tinggal.

\begin{tabular}{ccc}
\hline Kategori & n & \% \\
\hline Usia & & \\
$60-70$ & 22 & 68,8 \\
$71-80$ & 8 & 25 \\
$81-90$ & 2 & 6,3 \\
\hline Gender & & \\
Laki-laki & 22 & 68,8 \\
Perempuan & 8 & 25 \\
\hline Suku & & \\
Batak & 17 & 53,1 \\
Sunda & 2 & 6,3 \\
Jawa & 3 & 9,4 \\
Ambon & 4 & 12,5 \\
Manado & 6 & 18,8 \\
\hline Pendidikan & & \\
SMP & 9 & 28,1 \\
SMA & 13 & 40,6 \\
D3 & 8 & 25 \\
S1 & 1 & 3,1 \\
S3 & 1 & 3,1 \\
\hline Rumah Tinggal & & \\
Rumah Sendiri & 29 & 90,6 \\
Rumah Anak & 3 & 9,4 \\
\hline
\end{tabular}

$$
\text { Berdasarkan data yang telah }
$$
dikumpulkan dari 32 responden, terdapat 22 orang (68.8\%) dengan rentan usia 60-70 tahun, sebanyak 8 orang (25\%) dengan rentan usia $71-$ 80 tahun dan 2 orang (6.3\%) dengan rentan usia 81-90 tahun. Terdiri dari 16 laki-laki dan 16 perempuan dengan presentasi masing-masing $50 \%$. Dengan presentasi suku terbanyak, yaitu suku Batak sebanyak 17 orang (53.1\%), suku Manado sebanyak 6 orang (18.8\%), suku Ambon sebanyak 4 orang (12.5\%), suku Jawa sebanyak 3 orang $(9.4 \%)$ dan suku Sunda sebanyak 2 orang (6.3\%). Presentasi terbanyak berdasarkan pendidikan addalah SMA sebanyak 13 orang (40.6\%), SMP sebanyak 29 orang (90.6\%) dan sebanyak 3 orang $(9.4 \%)$ bertempat tinggal dirumah anak.

\section{Tabel 2. Dukungan Keluarga dan Kualitas} Hidup Lansia

\begin{tabular}{ccc}
\hline Kategori & $\mathbf{N}$ & $\%$ \\
\hline Dukungan Keluarga & & \\
Sedang & 1 & 31 \\
Buruk & 31 & 96,9 \\
\hline Kualitas Hidup & & \\
Sedang & 14 & 43,8 \\
Baik & 18 & 56,3 \\
\hline
\end{tabular}

Berdasarkan data pada tabel 2 dapat dilihat bahwa $96.9 \%$ responden mendapat dukungan keluarga dalam kategori buruk, dan hanya $3.1 \%$ yang mendapat dukungan keluarga dalam kategori cukup. Terdapat $56.3 \%$ responden 
memiliki kualitas hidup yang baik dan sisanya sebanyak $43.8 \%$ dalam kategori cukup.

Tabel 3. Hubungan Dukungan Keluarga Terhadap Kualitas Hidup Lansia

\section{Dukungan keluarga Kualitas Hidup}

\section{Koefisien}

Korelasi

1,000

0,204

Sig. (2-

tailed)

0,264

$\mathrm{N}$

Korelasi

32

32

Sig. (2-

tailed)

0,204

1,000

$\mathrm{N}$

32

32

Berdasarkan hasil uji statistik dengan menggunakan uji korelasi Spearman-rho, data pada table 3 menunjukkan bahwa tidak terdapat hubungan yang signifikan antara dukungan keluarga dengan kualitas hidup lansia, dengan nilai koefisien korelasi 0,204 (sig > 0,05)

\section{PEMBAHASAN}

Data pada tabel 2 menunjukkan bahwa walaupun sebagian besar responden mendapatkan dukungan keluarga dalam kategori rendah namun kualitas hidup lansia dalam kategori cukup dan baik. Hal ini berarti bahwa ada faktor-faktor lain yang dapat mempengaruhi kualitas hidup lansia. Menurut (Hayulita et al., 2018) faktor-faktor yang mempengaruhi kualitas hidup lansia adalah faktor kesehatan fisik, faktor psikologis dan spiritual, faktor hubungan sosial dan ekonomi, dan faktor keluarga. Menurut penelitian yang dilakukan oleh (Indrayani, 2018) bahwa faktor yang paling dominan dalam mempengaruhi kualitas hidup lansia adalah dukungan keluarga. Namun, dalam penelitian ini tidak ada hubungan yang signifikan antara dukungan keluarga terhadap kualitas hidup. Kualitas hidup yang baik dalam penelitian ini dapat dipengaruhi karena sebagian besar lansia yang masih memiliki kesehatan yang baik.

Tabel 3 menunjukkan bahwa dukungan keluarga tidak ada hubungannya dengan kualitas hidup lansia. Hasil ini mendukung hasil penelitian sebelumnya, seperti yang dilakukan oleh (Purwitaningtyas \& Prayidno, 2018) terhadap 45 orang lansia di Desa Sumbergondo Kecamatan Glenmore Kabupaten Banyuwangi bahwa tidak ada hubungan yang signifikan antara dukungan keluarga dengan peningkatan kualitas hidup. Penelitian lain juga menunjukkan hal yang sama pada penelitian yang dilakukan oleh Khasanah, (2019) terhadap 72 responden, bahwa tidak ada hubungan antara dukungan keluarga dengan kualitas hidup lansia. Penelitian yang dilakukan pada lansia penderita hipertensi, menunjukkan bahwa tidak ada pengaruh dukungan keluarga terhadap kualitas hidup (Potoboda, 2017). Tidak adanya hubungan dukungan keluarga dengan kualitas hidup lansia dapat dipengaruhi faktor pendukung lainnya seperti faktor fisik, psikologis, social dan lingkungan tempat tinggal lansia (Jacob \& Sandjaya, 2018). 
Peneliti beranggapan bahwa dukungan keluarga yang buruk namun lansia memiliki kualitas hidup yang baik dapat disebabkan oleh lingkungan tempat tinggal lansia yang bersahabat. Lingkungan yang bersahabat dan dapat menerima lansia, serta bagaimana lansia mampu menyesuaikan dirinya dengan kemunduran yang dialami dapat mempengaruhi kualitas hidup (Khorni, 2017). Sebagian lansia yang masih memiliki pasangan karena cenderung memiliki kontrol hidup yang baik, memiliki teman untuk bercerita, aktif serta dapat melakukan aktivitas sehari-hari secara mandiri memiliki kualitas hidup yang lebih besar (Kaur et al., 2015). Sebagian besar lansia juga memiliki kesehatan fisik yang baik sehingga lansia dapat menikmati hal-hal yang penting dalam hidupnya.

$$
\text { Hasil dalam peneltian ini }
$$
bertolakbelakang dengan hasil penelitian yang dilakukan oleh (Wafroh et al., 2017) bahwa dukungan keluarga mempunyai hubungan terhadap kualitas hidup lansia. Kondisi ini dikarenakan lansia puas dengan apa yang dicapai dalam kehidupannya serta memiliki kesempatan untuk mencintai dan dicintai dan memiliki banyak teman dalam hidupnya. Adanya hubungan dukungan keluarga terhadap kualitas hidup pada penelitian ini dikarenakan lansia merasa dirinya diperhatikan oleh keluarga dan mencukupi kebutuhan hidupnya.

\section{KESIMPULAN}

Setelah analisis data dan pembahasan sebelumnya dapat disimpulkan bahwa tidak terdapat hubungan antara dukungan keluarga terhadap kualitas hidup lansia. Lansia dapat mempunyai kualitas hidup yang baik meskipun kurang mendapat dukungan dari keluarga.

\section{SARAN}

Saran yang dapat disampaikan peneliti adalah agar penelitian selanjutnya diharapkan dapat membahas berbagai faktor dimensi dari kualitas hidup untuk dapat mengetahui dengan jelas dimensi mana yang paling berpenngaruh terhadap kualitas hidup pada lansia. Peneliti juga menyarankan agar keluarga dapat lebih memberikan dukungan kepada lansia untuk meningkatkan kualitas hidup lansia.

\section{REFERENSI}

BPS Kota Bogor. (2019). KOTA BOGOR DALAM ANGKA Bogor Municipality in Figures 2019 (Badan Pusat Statistik Kota Bogor (ed.)). BPS Kota Bogor/BPS-

Statistic of Bogor Municipality. https://bogorkota.bps.go.id/publication/do wnload.html?nrbvfeve=MTZlMWYwNzdi ZjZjNWNhYzY2NWI0MzY4\&xzmn=aH R0cHM6Ly9ib2dvemtvdGEuYnBzLmdvL mlkL3B1YmxpY2F0aW9uLzIwMTkvMD gvMTYvMTZlMWYwNzdiZjZjNWNhYz Y2NWI0MzY4L2tvdGEtYm9nb3ItZGFsY 
W0tYW5na2EtMjAxOS5odG1s\&twoadfn oarfeauf=MjAyMC0xMC0yMCAyMTo0 MjoyMg\%3D\%3D

Hayulita, S., Bahasa, A., \& Sari, A. N. (2018).

Faktor Dominan Yang Berhubungan

Dengan Kualitas Hidup Lansia. Afiyah, 5(2), 42-46.

https://doi.org/10.17605/OSF.IO/FR85N

Imanda, R. N. (2016). Strategi Peningkatan Quality of Urban Life ( QoUL ) dengan Pertimbangan Tingkat Kepuasan Masyarakat terhadap Kota Tempat Tinggal. Temu Ilmiah Iplbi, 193-200.

https://temuilmiah.iplbi.or.id/wpcontent/uploads/2016/12/IPLBI2016-E193-200-Strategi-Peningkatan-Quality-ofUrban-Life-QoUL-dengan-PertimbanganTingkat-Kepuasan-Masyarakat-0.pdf

Indrayani, S. R. (2018). Faktor-Faktor Yang Berhubungan Dengan Kualitas Hidup Lansia Di Desa Cipasung Kabupaten Kuningan Tahun 2017. Jurnal Kesehatan Reproduksi, 9(1), 69-78. https://doi.org/10.22435/kespro.v9i1.892.6 $9-78$

Jacob, D. E., \& Sandjaya. (2018). Faktor Faktor yang Mempengaruhi Kualitas Hidup masyarakat Karubaga district Sub District Tolikara Propinsi Papua. Jurnal Nasional Ilmu Kesehatan (JNIK), 1(69), 1-16. https://journal.unhas.ac.id/index.php/jnik/a rticle/view/4281
Kaakinen, et al. (2010). FAMILY HEALTH CARE NURSING. In Public Health. https://doi.org/10.1016/S00333506(59)80093-7

Kathiravellu, S. C. K. (2016). Hubungan Status Depresi terhadap Kualitas Hidup Lansia di Wilayah Kerja Puskesmas Petang II Kabupaten Badung Bali Tahun 2015. Intisar Sains Medis, 6(1), 92-101. https://doi.org/10.15562/ism.v6i.24

Kaunang, et al. (2019). Gambaran Tingkat Stres Pada Lansia. Gambaran Tingkat Stres Pada Lansia, 7(2).

https://ejournal.unsrat.ac.id/index.php/jkp/a rticle/view/24475

Kaur, H., Kaur, H., \& Venkateashan, M. (2015). Factors determining family support and quality of life of elderly population.

International Journal of Medical Science and Public Health, 4(8), 1049.

https://doi.org/10.5455/ijmsph.2015.21012 015220

Khasanah, N. (2019). Hubungan dukungan Keluarga Dengan Kualitas Hidup Pasien Diabetes Melitus Tipe II Di Puskesmas Gamping II. http://digilib2.unisayogya.ac.id/xmlui/bitstr eam/handle/123456789/124/NASKAH PUBLIKASI NUR KHASANAH.pdf?sequence $=1 \&$ isAllowed $=\mathrm{y}$ 
Khorni, S. (2017). Hubungan Antara Dukungan Keluarga Dengan Kualitas Hidup di Desa Gonilan Kecamatan Kartasura kabupaten Sukoharjo. Naskah Publikasi, 1-10. http://eprints.ums.ac.id/51307/1/Naskah Publikasi.pdf.pdf

Kiik, S. M., Sahar, J., \& Permatasari, H. (2018). Peningkatan Kualitas Hidup Lanjut Usia (Lansia) Di Kota Depok Dengan Latihan Keseimbangan. Jurnal Keperawatan Indonesia, 21(2), 109-116. https://doi.org/10.7454/jki.v21i2.584

Lara, A. G., \& Hidajah, A. C. (2017). Hubungan Pendidikan, Kebiasaan Olahraga, Dan Pola Makan Dengan Kualitas Hidup Lansia Di Puskesmas Wonokromo Surabaya. Jurnal PROMKES, 4(1), 59. https://doi.org/10.20473/jpk.v4.i1.2016.5969

Luthfa, I. (2018). Perbedaan Kualitas Hidup Lansia Yang Tinggal Bersama Keluarga Dengan Lansia Yang Tinggal Di Rumah Pelayanan Sosial. Wacana Kesehatan, 3(1). http://jurnal.akperdharmawacana.ac.id/inde x.php/wacana/article/view/66

Maylasari, Rachmawati, Y., Wilson, H., Nugroho, S. W., Sulistyowati, N. P., \& Dewi, F. W. R. (2019). Katalog: 4104001 Statistik Penduduk Lanjut Usia 2019. Badan Pusat Statistik.

Ningrum, Tita Puspita. Okatiranti. Wati, D. K.
K. (2017). Hubungan Dukungan Keluarga

Dengan Kualitas Hidup Lansia ( Studi

Kasus : Kelurahan Sukamiskin Bandung ).

Jurnal Keperawatan BSI, V(2), 6.

Octaviani, R. (2017). Hubungan Dukungan Keluarga dengan Kualitas Hidup Lanjut Usia Pasca Stroke Di Wilayah Kerja Puskesmas Gajahan Surakarta. Jurnal Universitas Muhammadiyah Surakarta, 3(2), 1-17. http://eprints.ums.ac.id/50831/1/NASKAH PUBLIKASI.pdf

Oktowaty, et al. (2018). Hubungan Fungsi Keluarga Dengan Kualitas Hidup Pasien Penyakit Kronis Degeneratif di Fasilitas Kesehatan Tingkat Pertama. Jurnal Sistem Kesehatan, 4(1), 1-6. https://doi.org/10.24198/jsk.v4i1.19180

Potoboda, D. C. (2017). No Title זт. 12-21. https://repo.unikadelasalle.ac.id/100/

Prima, D. R., Safirha, A. A., Nuraini, S., \& Maghfiroh, N. (2019). Pemenuhan Kebutuhan Lansia Terhadap Kualitas Hidup Lansia Di Kelurahan Grogol Jakarta Barat. Jurnal Kebidanan, 8(1), 1-7. https://doi.org/10.35890/jkdh.v8i1.115 Purwitaningtyas, R. yulia, \& Prayidno, S. H. (2018). Hubungan Dukungan Keluarga Terhadap Peningkatan Kualitas Hidup Lansia Di Desa Sumbergondo Kecamatan Glenmore Kabupaten Banyuwangi. 402- 
407. http://e-

journal.akesrustida.ac.id/index.php/jikr/arti cle/view/111

Radiani, Z. F. (2018). HUBUNGAN

DUKUNGAN KELUARGA DENGAN

KUALITAS HIDUP LANSIA YANG

MENGALAMI HIPERTENSI DI

WILAYAH KERJA PUSKESMAS

MANDALLE KABUPATEN PANGKEP.

Director, 15, 2017-2019.

https://doi.org/10.22201/fq.18708404e.200

4.3.66178

Uddin, M. A., \& Bhuiyan, A. J. (2019).

Development of the family support scale

(FSS) for elderly people. MOJ

Gerontology \& Geriatrics, 4(1), 17-20.

https://doi.org/10.15406/mojgg.2019.04.00

170

Wafroh, S., Herawati, H., \& Lestari, D. R. (2017). Dukungan Keluarga Dengan Kualitas Hidup Lansia Di Pstw Budi Sejahtera Banjarbaru. Dunia Keperawatan, $4(1), 60$.

https://doi.org/10.20527/dk.v4i1.2553

Wikananda, G. (2017). Hubungan Kualitas

Hidup dan Faktor Resiko pada Usia Lanjut di Wilayah Kerja Puskesmas Tampaksiring 1 Kabupaten Gianyar Bali 2015. Intisari

Sains Medis, 8(1), 1-12.

https://doi.org/10.15562/ism.v8i1.112

WPP. (2019). World Population Prospects 2019.
In Department of Economic and Social

Affairs. World Population Prospects 2019.

The United Nations.

https://population.un.org/wpp/Publications/

Files/WPP2019_Highlights.pdf 